$$
\text { Pontifícia Universidade C Católica }
$$

Alexandre Magno Castañon Guimarães

Empresas de Gestão Conservadora: Potencial da Previsão de Demanda e Simulação Computacional

Dissertação de Mestrado

Dissertação apresentada como requisito parcial para obtenção do grau de Mestre (opção profissional) pelo Programa de Pós-Graduação em Engenharia de Produção do Departamento de Engenharia Industrial da PUC-Rio.

Orientador: Prof. Dr. Madiagne Diallo

Rio de Janeiro Setembro de 2008 


$$
\begin{gathered}
\text { Pontifícia Universidade } \\
\text { Do Rio de Janeiro }
\end{gathered} \text { Cólica }
$$

Alexandre Magno Castañon Guimarães

\section{Empresas de Gestão Conservadora: Potencial da Previsão de Demanda e Simulação Computacional}

Dissertação apresentada, como requisito parcial à obtenção do título de Mestre em Logística (opção profissional) pelo Programa de Pós-Graduação em Engenharia Industrial da PUC-Rio. Aprovada pela Comissão Examinadora abaixo assinada.

Prof. Dr. Madiagne Diallo Orientador Departamento de Engenharia Industrial - PUC-Rio

Prof. Dr. Augusto Cesar de Carvalho Peres

CENPES - Petrobrás

Dr. Roberto da Costa Lima Instituto de Pesquisas da Marinha - IPqM

Prof. Dr. Marcus Vinicius Pereira de Souza

Centro de Ensino Superior de Juiz de Fora

Prof. Dr. José Eugenio Leal

Coordenador Setorial do Centro Técnico Científico - PUC-Rio

Rio de Janeiro, 01 de setembro de 2008 
Todos os direitos reservados. É proibida a reprodução total ou parcial do trabalho sem autorização da universidade, do autor e do orientador

\section{Alexandre Magno Castañon Guimarães}

Graduou-se em Engenharia Química na Universidade Federal do Rio de Janeiro em 1988. Cursou Pós - Graduação no curso de Especialização em Engenharia Econômica e Administração Industrial pela Universidade Federal de Rio de Janeiro em 2000. Trabalha aproximadamente há 20 anos na indústria no segmento de vedação e isolamento térmico. Nos últimos 12 anos tem atuado como gerente de produção com ênfase em Planejamento, Projeto e Controle de Sistemas de Produção.

Ficha Catalográfica

Castañon Guimarães, Alexandre Magno

Empresas de gestão conservadora: potencial da previsão de demanda e simulação computacional / Alexandre Magno Castañon Guimarães ; orientador: Madiagne Diallo. - 2008.

100 f. ; $30 \mathrm{~cm}$

Dissertação (Mestrado em Engenharia Industrial) Pontifícia Universidade Católica do Rio de Janeiro, Rio de Janeiro, 2008.

Inclui bibliografia

1. Engenharia industrial - Teses. 2. Previsão. 3. Séries temporais. 4. Demanda. 5. Simulação. 6. Recursos. 7. Arena. 8. Statgraphics. I. Diallo, Madiagne. II. Pontifícia Universidade Católica do Rio de Janeiro. Departamento de Engenharia Industrial. III. Título.

CDD: 658.5 


\section{Agradecimentos}

A minha esposa Heloísa e aos meus filhos Isabela e André.

A minha mãe (In Memoriam).

Ao meu orientador Madiagne Diallo.

A minha amiga Ana Maria que me ajudou em todos os momentos.

Aos professores e colegas do mestrado pela ajuda e troca de experiências.

A todos aqueles que de uma maneira direta ou indireta me ajudaram. 


\section{Resumo}

Castañon Guimarães, Alexandre Magno; Diallo, Madiagne (Oreintador). Empresas de Gestão Conservadora: Potencial da Previsão de Demanda e Simulação Computacional. Rio de Janeiro, 2008. 100p. Dissertação de Mestrado (opção profissional) - Departamento de Engenharia Industrial. Pontifícia Universidade Católica do Rio de Janeiro.

Esta dissertação tem como objetivo mostrar o potencial da aplicação das ferramentas Previsão de Demanda e Simulação Computacional em uma unidade produtiva com administração de característica familiar, que não adota as modernas técnicas propostas por especialistas para a gestão da cadeia de suprimento. Para isso, foram abordados os conceitos e os aspectos fundamentais, bem como as principais etapas, os benefícios, as limitações e as dificuldades da utilização dessas ferramentas. Além disso, foi proposta uma metodologia que aumentou a precisão da Previsão de Demanda. Com os dados obtidos foi possível analisar o desempenho dos fluxos dos processos simulados, o que permite auxiliar na gestão dos recursos, levando-se em conta principalmente a variabilidade da demanda e as incertezas dos mercados. Nessas análises foram utilizados os softwares Statgraphics Centurion e Arena a fim de elaborar, respectivamente, os modelos de previsão de demanda e de simulação computacional para o estudo de caso proposto.

\section{Palavras-chave}

Previsão, Séries Temporais, Demanda, Simulação, Recursos, Arena, Statgraphics. 


\section{Abstract}

Castañon Guimarães, Alexandre Magno. Conservative Managed Enterprises: Demand Forecast and Computer Simulation Potential. Rio de Janeiro, 2008. 100p. Dissertação de Mestrado (opção profissional) - Departamento de Engenharia Industrial. Pontifícia Universidade Católica do Rio de Janeiro.

This thesis aims to show the potential of the Demand Forecast and Computer Simulation techniques carried out in a manufacturing plant with family administration feature that does not use the modern techniques proposed by Supply Chain management experts. In order to study the subject; concepts, fundamental principles, important steps, advantages, limitations as well as the difficulties of using those tools were investigated. In addition, a new method was proposed which resulted in the improvement of the demand forecast accuracy. With the forecasted data, it was possible to analyze the performance of the simulated manufacture flows. Such procedures improved the management of resources while the demand variability and the uncertainties of markets were considered. The Statgraphics Centurion and Arena softwares were used in order to developed, respectively, models for Demand Forecast and Computer Simulation for the study proposed.

\section{Keywords}

Forecasting, Time Series, Demand, Simulation, Resources, Arena, Statgraphics. 


\section{Sumário}

1 Introdução 11

1.1 Apresentação 11

$\begin{array}{ll}1.2 \text { Objetivo } & 12\end{array}$

$\begin{array}{ll}1.3 \text { Organização do documento } & 13\end{array}$

2 Fundamentos Teóricos $\quad 15$

2.1 Previsões de Demanda $\quad 15$

2.1.1 Modelos de Previsão de Demanda 16

2.1.2 Métodos de Cálculo dos Erros de Previsão de Demanda 28

2.1.3 Software de Previsão de Demanda 29

2.1.4 Aplicação da Previsão de Demanda 30

2.2 Simulação Computacional 31

2.2.1 Alternativas de abordagem $\quad 32$

2.2.2 Software de Simulação Computacional 34

2.2.3 Aplicação da Simulação 36

3 A Empresa $\quad 41$

3.1 Áreas de Atuação 41

3.2 Mercados de Atuação $\quad 42$

3.3 Características Estruturais $\quad 42$

3.4 Características Operacionais 43

4 Previsão de Demanda 45

4.1 Descrição geral dos Mercados da Unidade Produtiva 45

4.2 Fluxo de informações 46

4.3 Coleta de Dados para Previsão de Demanda $\quad 52$

4.4 Metodologias Propostas $\quad 54$

4.4.1 Apresentação da Metodologia para o Mercado A $\quad 59$

4.4.2 Comparação entre os Métodos I e II 69

4.5 Considerações

5 Simulação Computacional $\quad 71$

5.1 Mapeamento do Processo $\quad 71$

5.2 Coleta de Dados para Simulação $\quad 75$

5.3 Modelo de Simulação Computacional 75

$\begin{array}{ll}\text { 5.3.1 Mercado A } & 77\end{array}$

$\begin{array}{ll}\text { 5.3.2 Mercado B } & 83\end{array}$

$\begin{array}{ll}\text { 5.3.3 Mercado C } & 85\end{array}$

$\begin{array}{ll}\text { 5.3.4 Mercado D } & 87\end{array}$

$\begin{array}{ll}\text { 5.3.5 Mercado E } & 89\end{array}$

5.4 Considerações 91

6 Conclusão 95

7 Referências Bibliográficas $\quad 97$ 


\section{Lista de figuras}

Figura 1: Séries temporais 25

Figura 2: Método iterativo apresentado por Box-Jenkins para determinar um modelo ARIMA

Figura 3: Modelo apresentado por Law e Kelton para avaliação de um

Sistema

Figura 4: Base conceitual da simulação apresentado por Pidd

Figura 5: Interligação da Flexibilidade e Especialização do Usuário em Simuladores

Figura 6: Fluxograma da Metodologia de Simulação 38

Figura 7: Custo acumulado do sistema com e sem simulação 40

Figura 8: Estrutura Organizacional da Fábrica do Estudo de Caso 43

Figura 9: Descrição dos Métodos I e II 53

Figura 10: Demanda Real, Previsão de Demanda e Resíduo - Modelo ARIMA(1,1,1) - Mercado A: Período 1 a $48 \quad 56$

Figura 11: Comparação dos Dados Reais com a Série ajustada Mercado A, Período 1 a $48 \quad 58$

Figura 12: Comparação dos Dados Reais com a Série ajustada Mercado B, Período 1 a $48 \quad 62$

Figura 13: Comparação dos Dados Reais com a Série ajustada Mercado C, Período 1 a $48 \quad 65$

Figura 14: Comparação dos Dados Reais com a Série ajustada Mercado D, Período 1 a 48

Figura 15: Comparação dos Dados Reais com a Série ajustada Mercado E, Período 1 a 48

Figura 16: Fluxograma do processo de fabricação da Placa de Vedação 73

Figura 17: Ilustração das entidades de entrada 77

Figura 18: Ilustração da junção dos kits para a formação da mistura 78

Figura 19: Ilustração da área de reator $\quad 79$

Figura 20: Ilustração da área de calandra $\quad 80$

Figura 21: Ilustração da área de acabamento e entrada ao APA 80

Figura 22: Representação ilustrativa da animação para a unidade de 81 Placa de Vedação 


\section{Lista de tabelas}

Tabela 1: Cálculo da Acurácia da Previsão 29

Tabela 2: Dados da Demanda do Mercado Tipo A 47

Tabela 3: Dados da Demanda do Mercado Tipo B 48

Tabela 4: Dados da Demanda do Mercado Tipo C 49

Tabela 5: Dados da Demanda do Mercado Tipo D 50

Tabela 6: Dados da Demanda do Mercado Tipo E 51

Tabela 7: Estimativa dos Erros MAD e MAPE para a série temporal de 48 períodos do Mercado A $\quad 54$

Tabela 8: Demanda Real versus Previsão de Demanda para o Período 155 a 48 - Mercado A

Tabela 9: Demanda Real versus Previsão de Demanda para o Período 49 - Mercado A 56

Tabela 10; Modelo Ótimo, Estimativa dos Erros MAD e MAPE e Previsão de Demanda para a série temporal do Mercado A em função do Período

Tabela 11: Determinação dos pontos atípicos para o Mercado A Período 1 a 48

Tabela 12: Modelo Ótimo, Estimativa dos Erros MAD e MAPE e Previsão de Demanda para a série temporal ajustada do Mercado A em função do Período

Tabela 13: Previsão de Demanda para o Mercado A - Métodos I e II 60

Tabela 14: Previsão de Demanda para o Mercado B - Métodos I e II 61

Tabela 15: Estimativa dos Erros MAD e MAPE para a série temporal ajustada de 48 períodos do Mercado B 62

Tabela 16: Previsão de Demanda para o Mercado C - Métodos I e II 64

Tabela 17: Previsão de Demanda para o Mercado D - Métodos I e II 67

Tabela 18: Previsão de Demanda para o Mercado D pelo Método II excluindo a demanda atípica nos períodos 50 e $52 \quad 68$

Tabela 19: Previsão de Demanda para o Mercado E - Métodos I e II 69

Tabela 20: Desempenho dos recursos para um cenário com 3 reatores e $\quad 82$ 
3 calandras - Mercado A

Tabela 21: Desempenho dos recursos para um cenário com 2 reatores e 2 calandras - Mercado A

Tabela 22: Distribuição probabilística dos processos - Mercado B

Tabela 23: Desempenho dos recursos para um cenário com 2 reatores e 3 calandras - Mercado B 85

Tabela 24: Distribuição probabilística dos processos - Mercado C 86

Tabela 25: Desempenho dos recursos para um cenário com 1 reator e 287 calandras - Mercado C

Tabela 26: Distribuição probabilística dos processos - Mercado D 88

Tabela 27: Desempenho dos recursos para um cenário com 1 reator e 189 calandra - Mercado D

Tabela 28: Distribuição probabilística dos processos - Mercado E

Tabela 29: Desempenho dos recursos para um cenário com 1 reator e 1 calandra - Mercado E

Tabela 30: Tempo de ocupação e quantidade de processos para atender a demanda do período 49

Tabela 31: Estrutura proposta para atender a demanda do período 49 